\title{
WestVirginiaUniversity
}

THE RESEARCH REPOSITORY @ WVU

Faculty \& Staff Scholarship

2001

\section{Practice in the Electronic Community}

Roger A. Lohmann

West Virginia University, roger.Iohmann@mail.wvu.edu

John McNutt

University of Delaware

Follow this and additional works at: https://researchrepository.wvu.edu/faculty_publications

Part of the Infrastructure Commons, Public Administration Commons, Scholarly Communication Commons, Scholarly Publishing Commons, Science and Technology Policy Commons, Social Policy Commons, Social Welfare Commons, and the Social Work Commons

\section{Digital Commons Citation}

Lohmann, Roger A. and McNutt, John, "Practice in the Electronic Community" (2001). Faculty \& Staff Scholarship. 2763.

https://researchrepository.wvu.edu/faculty_publications/2763

This Article is brought to you for free and open access by The Research Repository @ WVU. It has been accepted for inclusion in Faculty \& Staff Scholarship by an authorized administrator of The Research Repository @ WVU. For more information, please contact ian.harmon@mail.wvu.edu. 


\section{Practice in the Electronic Community ${ }^{1}$}

Roger A. Lohmann

West Virginia University

John McNutt

Boston College

\section{Introduction}

The Internet, like community practice, has frequently been put forth as a force for Progressive social change during its short but eventful life history . With the Internet the record to date is decidedly mixed. The potential is certainly there for this amazing technology to advance the causes of human freedom well-being and community. At the same time, however, this powerful set of technologies that in less than a decade have become nearly universal in scope and sweep, have the potential also to become simply another extension of the global economic marketplace. Far worse, it also has the potential to become a power tool for class domination or a simple reinforcement of existing and future inequalities.

The Internet was at its inception a commons rather than a marketplace (Lohmann, 1992). It was originally born out of the collaborative interest of the international community of physical scientists for easier and more effective ways of collaborating in sharing their research results. Scientists like Tim Berners Lee the author of HTML and the web protocol http were primarily seeking ways to improve scientific collaboration. Very quickly, it was apparent that the ease of use which the world wide web granted physicists could also have major implications for enhancing democracy [Benton Foundation] or for improving communication between isolated members of a community.

Increasingly, however, these communitarian notions have been overwhelmed by images and ideas of the internet as one huge shopping arcade. It is well to remember here the difference between hype and reality. Even before the dot.com market meltdown of 2000, the actual track record of e-commerce and business-to-business solutions was just as spotty and equivocal as any of the assorted Progressive experiments in promoting electronic democracy or community via the internet. They just have much larger advertising budgets. For every clear-cut internet success story that is publicly celebrated there are 50 "highly promising" possibilities, 100 "interesting innovations" that didn't pan out and 10 workable innovations largely unknown to anyone but their creators.

\footnotetext{
${ }_{1}$ A revised version of this manuscript was published as Practice in the Electronic Community. Encyclopedia of Community Practice. Marie Weil, editor. Sage. 2001. 636-645.
} 
The sudden growth of the internet has meant that some old favorites, like the Foundation Center Library (foundationcenter.org) and the Grantsmanship Center (www.tgc.com) can now also be found online, along with newer or more local resources such as Guidestar's online listing of tax exempt organizations (www.guidestar.org) and The Maine Philanthropy Center (http://www.megrants.org/). The internet has also been a major boon to recent protest movements like the anti-World Trade Organization movement, which has is linked by a variety of web sites like www.wtowatch.org/ and www.tradewatch.org/.

In this brief article, we examine several developments in online technology and resources which appear to hold great potential for advancing human well-being and social justice. Community organization applications of internet technology have already manifested some important portion of that potential in recent years. The topics we will examine are, in order of presentation, electronic communication and networking, electronic advocacy, fund raising support, geographic information systems and data base management. We conclude this brief article with a brief discussion of information poverty and the growing disparity of information haves and have-nots.

\section{Electronic Community}

Looking back to its early history (still less than a decade ago), few people were prepared or had anticipated the powerful potential of this new medium for social interaction, social integration, reinforcing a sense of social solidarity and building social capital. There is an obvious mathematical illusion in the label computer, and an astonishingly broad range of other functions associated with digital technology. However, there can be no denying that computer technology already ranks with the pen, the telephone and the printing press as fundamental aids to human communication. The networked computer is able to rival the pen and the telephone for one-to-one communications. Moreover, like the printing press, the computer seems uniquely suited to low-cost one-to-many communications. But, unlike all previous technologies, the capabilities of a network of computers for many-tomany and many-to-one communications are unprecedented. It is the combination of these overlays of communications possibilities that have given rise to the idea of electronic, or virtual community (Rheingold, 1993).

"Electronic community" is a generic term that can be applied to a very broad range of endeavors in cyberspace. E-mail, discussion lists (many to many email), targeted mailings (one-to-many email), tele-communities, portals, chatrooms and other groupware, to name just a few. 


\section{Email, Lists and Electronic Community}

One of the most important media of electronic community, if not the most elegant technologically, is the lowly but ubiquitous email message. Its origins are in the combination of a text editor, a network connection and a few simple behind-the-scenes commands to manage the basic store-and-forward technology involved. From it we have gotten news groups; electronic discussion lists (almost universally mislabeled "list serves" after the software that distributes messages to such lists); chat rooms; and a host of other permutations on this basic idea. Email tends to come in two basic flavors: POP (Post Office Protocol), in which messages are automatically delivered to and stored on the user's desktop computer, and IMAP (Internet Message Access Protocol), in which messages remain on a central server and are read by the users machine.

Some discussion lists (ARNOVA-L [1991] and ACOSA-L [1993] ) are, by design, venues for general discussion by a national or international community academics and practitioners, sponsored by specific organizations and used, in part, for membership recruitment purposes. Others, like the array of "Charity Channels" (www.charitychannels.com) hosted by the conservative American Philanthropy Review offer large lists on very narrow topics. Another completely different approach is that of professional historians where a grant-funded network of topical lists are moderated by specialists in that area. These moderators review and approve messages (mostly for civility, they claim; historians must be a testy bunch!) before they are forwarded to the list, thereby performing a function not unlike that of journal editors.

Given its widespread use (or perhaps because of it) email technology has remained a fairly static medium for the better part of a decade. Certainly, there have been vast improvements in software for sending, retrieving, viewing and storing email messages. Qualcomm's Eudora, Microsoft's Outlook, Outlook Express and Entourage, Netscape Communicator and other latest generation email clients offer a broad array of support services for the convenience of the email user. (Entourage, available only on the Macintosh at this writing, combines a unique feature by which clicking on any address in an online user's address book brings up a street map locating that address from the MSN Expedia service.) But the underlying POP3 (for messages placed directly on the user's machine) and IMAP (for messages left on a central server) standards represent mature, stable technologies that most users are unlikely to move away from anytime soon, despite a host of rival technologies, including NetMeetings, WebCams. And, most recently, Groove.

Some users in large organizations and institutions now receive their email through integrated groupware solutions like Notes and Groupwise, which combine enhanced email service with group calendaring and other services. 
The centralized nature of groupware services makes them inherently more suitable for a single bureaucracy than for groups in a decentralized or pluralistic community, however. One possibility at the time of this writing that could move community users away from basic email is the Groove technology (www.groove.net) released by a group headed by Ray Ozzie, one of the original developers of Lotus Notes. The Groove browser is free and the program is said to be a decentralized approach, like the Napster musicsharing phenomenon, and yet allow active collaborations like other groupware. Whether it will catch on and eventually replace existing email or discussion lists remains to be seen.

\section{The Telecommunities Movement}

One electronically-based social movement with particular importance for the history of community organization was the telecommunities movement of the mid-1990's (Schuler, 1996). A testament to the pace of social change on the internet is the way this movement sprung up, flourished and died in a space of less than five years. Before market realities brought a halt to such ventures, Apple Computer sponsored two national conferences on telecommunities in 1995 and 1996. The University of Victoria sponsored an international community networking conference. (All that remains today of this movement, which in its prime had a heavily electronic democracy slant to it, is a variety of chamber of commerce style web sites marketing local communities.)

One of the most interesting and far-reaching of these developments was the Blacksburg Electronic Village project (www.bev.net ) which sought to wire and link an entire city in the 50,000 range. Another interesting community-level efforts of this type include Charlotte's Web in Charlotte NC (www.charweb.org) which is no longer operational. Still another is the La Plaza Telecommunity in Taos NM (www.laplaza.org) which is still operational. Many of the telecommunity ventures from the mid-1990's, like Charlotte's Web have simply ceased operations, while others have been folded into the Chamber of Commerce operations of local communities and become e-commerce sites for main street businesses Even so, there are still nearly 100 known community networks at this time, and HUD is still funding neighborhood networks.

While they may be doomed in the long run, the body is not yet cold. Something of the spirit of this movement can still be discerned from the Nevada Missouri site, which still bills itself as "America's First Telecommunity." (ctr.cstp.umkc.edu/NevadaTelecommunity/). Like Blacksburg, Nevada and Taos, many of the communities developing the telecommunity notion were (and are) small or medium sized cities. Austin Texas may have been one of the largest urban centers to develop this idea (www.ci.austin.tx.us/telecom/intelcom.htm). 
One telecommunity which remains operational on a statewide basis is a small, rural state is the West Virginia Information Service (WISe), a statewide nonprofit telecommunity funded by the Benedum Foundation and operated by the public television station in Morgantown VW (www.wvwise.org). WISe continues to link community organizers and nonprofit organizations throughout the state of West Virginia, and serves as a primary email post office for many of them. It's 800 numbers, easily configured First Class server and widely disseminated client software make it feasible for even novice computer users to establish and operate comparable telecommunities.

There have been a number of similar ventures to create a sense of electronic community on the national level. One such group is the Organizers' Collaborative, created in 1999. www.organizenow.net Their mission is to help non-profit and activist groups all over the United States more effectively use computers and the Internet to achieve social change, primarily in three areas: creating websites to promote social change networking and resource sharing, studying the impact of the Internet on social justice efforts, and developing software tools and printed "how-to" resources.

\section{Advocacy and Technology}

Advocacy is a core function of community practice. In the past few years, technology has created a sea change in the nature of advocacy related practice. Advocates of every stripe are creating websites, developing e-mail contact lists and experimenting with new types of technology. A well-known example is Censure and Move On (www.moveon.org) started during the Clinton Impeachment process. This section will discuss this emerging technology and important development.

These new methods of advocacy are often referred to as Electronic advocacy (Fitzgerald \& McNutt, 1999; McNutt \& Boland, 1999), Netactivism (Schwartz, 1996), Virtual Activism (Krause, Stein \& Clark, 1998) and Cyberactivism (Bennett \& Fielding, 1999). All of these designations refer to use of highly sophisticated communications technology to influence the decision making process (McNutt \& Penkaukaus, 2000). While in most cases this means Internet-related technology (also called New Media), it can mean other types of interventions as well.

The most commonly used interventions appear to be e-mail strategies (including discussion lists and distribution lists) and web-based strategies. Combined with earlier techniques, such as conference calling and faxing, they represent the current advocacy array. More sophisticated and adventurous organizations are experimenting with technologies like streaming video, online surveys, on-line fundraising and even webcasting. 
The advantages of these new methods include extending the reach of advocacy efforts, overcoming barriers of time and distance and decreasing the transaction costs of organizing. In the face of changes in the policy framework facing communities today (devolution, decentralization and so forth), these assets can carry considerable weight.

There is considerable evidence that these techniques are earning their place in the advocacy enterprise (McNutt, 2000). First, these techniques are the subject of considerable press coverage (Drinkard, 1999, August 31). This is especially true of pathbreaking efforts such as "Censure and Move On [www.moveon.org]". Second, material on these techniques have appeared in standard books on advocacy (Smucker, 1999; Haynes \& Mickelson, 2000). Third, there is the response of the political consulting community, many of whom have established Internet capability. Campaigns and Elections, a major news organ for this group has initiated a regular monthly section entitled "Bandwagon", which deals solely with these issues. Forth, a number of studies have established that these techniques are being used in advocacy practice (see McNutt \& Boland, 1999; Rees, 1999). Finally, groups such as the Benton (www.benton.org) and Markle (www.markle.org) Foundations, OMB watch (www.ombwatch.org) and others have created programs to promote this type of practice.

Since this is a practice in its formative stages, there is little theory to guide practitioners. McNutt \& Penkauskas (2000) argue that there are four major process in the practice of electronic advocacy: research, organizing/collaboration, public information and applying pressure.

Research about issues, strategies and opponents is fundamental to social action. It can be facilitated by the quick response of on-line databases and inquiries via e-mail. Technology can also facilitate on-line surveys and the analysis of data with statistical software, spreadsheets and Geographic Information Systems technology. The on-going collection of information is valuable and can support subsequent processes in an overall effort.

Informing the public about the nature of the policy or program issue or a social problem logically follows from developing the information. Websites and e-mail are very good at reaching a large number of people quickly and inexpensively. Some organizations are experimenting with video teleconferencing, webcasting and streaming video (Turner, 1998).

Organizing and coordinating action are vital to any change effort. They are also among the most costly activities in terms of time and money. Again, e-mail and websites provide the ability to organize quickly at minimal costs (Schwartz, 1996). On-line fundraising can also support this process by developing the funding base that is critical to any organizing effort. Some organizations are developing secure Intranets (secure internal Internet-like systems) to facilitate coordination. 
Finally, applying pressure to decision-makers is a key part of social change. This often means giving supporters the responsibility of sending letters or faxes to decision-makers (Faxing can be done through a website). The evidence on the effectiveness of e-mail messages to decision-makers is unclear. Three studies of national level legislative offices paint a less than enthusiastic picture of the viability of e-mail Vs more traditional methods (Bonner, 1998, Davis, 1999; Lemmon, P. \& Carter, M. (1998). On balance, McNutt, Lima, Penkaukaus \& Rusoff (1999) at the state level in Massachusetts arrived at more positive results. This is, perhaps, the reason that many practitioners council the integration of these techniques with more traditional methods. Websites offer some potential to influence decision makers by providing a ready source of information On-line petitions and report cards seem to be the emergent techniques in this area.

Developing An Effort: Organizations that plan to develop electronic advocacy systems should realize that careful planning is essential to develop an effective operation (see Schwartz, 1996; Bennett \& Fielding, 1999) . While this is a practice that depends on technology it is primarily a people oriented process as opposed to a technology-oriented process. It is essential to build two complementary structures: the human organization that conducts the advocacy and the technical system that supports this endeavor.

Creating the human organization requires integration with the overall operation of the parent group, particularly the government relations or advocacy functioning. It is important that strategies and tactics harmonize with overall planning. It is also important to incorporate the knowledge base that the organization has developed on the relevant political systems into the planning effort. In order for the technology to function effectively, good training and technical support are essential.

The technology arrangements should support the overall advocacy strategy and must be dependable and easy to use. Many of these technologies can support other functions of the organization, a fact that needs to be carefully considered in the planning effort. It us usually true that less complex technologies that are similar to existing systems are more likely to be adopted (Rogers, 1995). It is probably better to start with a less sophisticated system that is scalable than to begin with a cutting edge system. Positive experience with these approaches can build the confidence needed for more sophisticated tasks.

Evaluating the results of the process is also important. This is one of the most difficult research situations because of the nature of advocacy goals and the multitude of factors contributing to any outcome.

Technology can revolutionize the practice of advocacy. It has the potential to promote social and economic justice in important and innovative ways. 


\section{Geographic Information Systems}

Geographic information systems (GIS) offer planners and organizers new and unparalleled ways to present and analyze data. These systems combine mapping with powerful demographic and programmatic databases through a technology known as "Geocoding" that allows the computer to integrate the two in a map that shows the distribution of a number of factors. There are two aspects of Geographical Information Systems that are of greatest interest to community practice: The first of these is to gather and correlate information with a spatial dimension or aspect. Thus, for example, it is straightforward to create maps of the spatial distribution of social problems like child abuse from data sets of police arrest records, agency abuse complaints, school truancy reports, etc. (all of which typically contain street addresses.) The second involves the use of geosynchronous technology to assist and guide organizing efforts. For example, event data for a regional, national or even local protest campaign might be plotted to show travel times and distances, sequencing and other information.

One need not get involved in elaborate high-tech systems in order to benefit, at least minimally, from this technology. A number of companies, including Rand-McNally, market inexpensive CD-ROM Disks that contain road and street maps of the entire U.S., accessible by name or zip code. A number of systems provide similar capacity over the web, such as MapQuest and Yahoo maps. One new program, Microsoft's Entourage builds such capabilities directly into its email client, and a number of automobile manufacturers offer geo-synchronous map readers as (relatively expensive) new car options. These can be used by urban and rural community organizers or other social workers doing home visits to locate specific addresses, plan routes, and for numerous other purposes as well. These maps are generally as detailed and accurate as they are inexpensive. In one recent instance, a suburban neighborhood association used these maps to supplement existing county maps submitted as part of a state highway redesignation project. In another instance, a colleague who formerly worked on the Navaho Reservation for a number of years used these maps to trace a number of road connections he had been unfamiliar with.

Sophisticated GIS software, however, has a variety of additional capabilities. One can use these programs in combination with census and other similar data to plot the exact location and geographic distribution of low (or middle or high!) income populations (Schlossberg, 1998). The painstaking labor that went into preparing the maps of the Halsted Street neighborhood published in Hull House Maps and Papers could be reduced significantly.

Another facet of GIS - the use of geo-synchronous technology-has immediate, practical implications for community practice as well as some longrange political implications that community practitioners ought to be far more alert to than they currently appear to be. The technology itself is extraordinarily easy to explain but highly sophisticated and expensive to put in place. At present there are 22 fixed-position satellites in orbit around the earth which together make it possible to triangulate (within a precision of inches) any physical position on the planet. 


\section{On-line Fund Raising}

Another important facet of the relation between community practice and the internet is the trend toward the development of on-line fund raising. From the 1920's, when current approaches to "federated financing" were initiated, to the present fund raising for human services in the U.S. has been largely community-based and under the control of nonprofit financial intermediaries like Community Chest and more recently United Way and its various alternatives. Payroll deduction and other aspects of "workplace giving" have been important components .

With the emergence of the desktop computer in the early 1980's, we began to see the development of specialized, fund-raising software. Generally, these software products have tended to be relational databases with a range of appropriate fields suitable for storing and quickly referencing data on potential donors. A small number of companies also offer the capability of managing both donations and membership records in the same database. Several companies also supply specialized software to support foundations, United Ways and other grant-makers and financial intermediaries. At least some of these databases can be synchronized with hand held devices, which together with features like wireless networking, make them potentially very useful in community practice settings. As of this writing, the technological capabilities in this area far exceed actual use in many community practice settings.

Beginning about 1998 entirely new, non-community-based alternatives based in the internet presence of giant commercial entities like America Online and Fidelity began to evolve entirely new forms of online fund raising. Since then reports of a great many successful campaigns carried out online have appeared in print in publications such as the Chronicle of Philanthropy. Within the United States, the American Red Cross has a particularly successful online fund raising operation and internationally millions were raised following an earthquake in India.

In general, these have been of four types, only three of which are legitimate: 1) Financial service companies like banks, brokerage houses, and investment services with existing electronic funds transfer (EFT) capabilities, for whom donations were a simple addition to a "full range" of financial services. 2) Internet service providers and portals, for whom the ability to function as a financial intermediary for donations offered one of many ways for companies to attempt to distinguish themselves from their competitors in increasingly tight markets. 3) Internet startup companies (a number of which succumbed to the various "market readjustments" which started early in 2000); and 4) Assorted online equivalents of the dubious and overtly fraudulent fund-raising operations that have long plagued this field. In almost all instances, the modus operandi of these new services is the same: in exchange for "a small fee" these firms will transfer donations from givers to 
designated 501-c-3 organizations (The fees charged can, in fact, very widely just like bank card charges and, for that matter, local United Way administrative and fund raising costs.)

As of this writing, this entire development is too new and untried to say a great deal more about it. Theoretically, the ease of on-line contributing has the potential to completely replace workplace giving, responses to conventional mail solicitations, and a variety of other more traditional forms of fund raising. A single online intermediary (e.g., AOL's helping.org) could conceivably replace the fund raising operations of all 2,000+ United Ways in the U.S. with a system that is cheaper, faster, and offers much more direct expression of donor preferences. In the process, much of what remains of the community social service planning network in the U.S. could also be seriously disrupted or undermined. However, such nightmares (or, dreams depending on your point of view) are seldom realized quite as anticipated, on the internet or elsewhere. About all that can be said at this point is that this is a tremendously fascinating and volatile arena in which significant developments may be occurring in the next few years.

\section{The Digital Divide}

One of the key information issues that community practitioners must confront is the emerging digital divide between the information "haves" and "have nots"(Kwikel \& Cnaan, 1991; McConnaughey, Everette, Reynolds \& Lader, 1999; Wrench, 1995; Wrench, 1996; Tropman, Erlich \& Rothman, 1995). In a knowledge-based economy, the lack of access to information may prove to be even more critical than limited financial resources in defining real poverty (Haywood, 1995; Lang \& St. John's University, 1988). While community practitioners in social work have been only slightly influenced by these ideas to date, there are a few indications that this information theory of poverty is already having some impact on the environment of community practice.

For example, in many states, governors and legislatures have endorsed or initiated projects to bring computers and network access to every school, and there have been a number of independent initiatives by nonprofit and community-based groups to widen availability to information technology to disadvantaged groups.

The more challenging part of this effort is to develop serious know-how in members of disadvantaged populations. One interesting project along these lines is the Technology Opportunities Program (formerly TIIAP) program in the commerce department. To date, one TOP grant has been awarded to the Division of Social Work at West Virginia University to broaden the availability of information technology to information-poor populations in 
rural Appalachia. This is, as far as we know, the only project of its kind funded to a social work education program.

It is relatively clear already that electronic technology is a powerful and effective tool in the hands of the wealthy and powerful. It is also clear, however, that electronic technology in and of itself is class- and interestneutral.

\section{Conclusion}

As with so many other facets of modern life, the practice of community organization is being changed in innumerable ways by the remarkable advance of internet technology. Despite a veritable avalanche of publicity about its commercial potential, the market meltdown in the second half of 2000 revealed that the online universe is far less securely a purely commercial venue than claimed. In particular, internet technology still holds vast untapped potential for community practice aimed at advancing the cause of human well-being and social justice. One highly promising set of potentials are in the ability of internet communications to escape the conventional limits of time and space, and to supplement the conventional categories of face-to-face, small group, speaker-to-audience, traditional letter writing and such one-way broadcast media as radio and television with an amazing new array of interactive capabilities.

One of the first venues in which some of these communications capabilities are being manifested is in the area of on-line advocacy. Another area with vast potentiality, but also significant implications for change, is the arena of on-line fund raising. Even as electronic communications may modify the place-boundedness of traditional community practice, the technologies of geographic information systems make it increasingly possible to do some interesting new things with conventional ideas of place. One of the major issues of social justice raised by these new technologies, however, is the large, and rapidly expanding, gap between information haves and have-nots. 


\section{References}

Bennett, D. \& Fielding, P. (1999). The Net Effect: How Cyber-Advocacy is Changing the Political Landscape. Merrifield, VA: E-Advocates Press

Bonner, J. (1998). The Internet and grassroots lobbying: the next wave. Campaigns and elections. 19 (9), 46-48.

Cwikel, J. \& Cnaan, R. Ethical dilemmas in applying second wave information technology to social work practice. Social Work, 1991, 36 (2), 114-120.

Davis, R. (1999). The Web of politics: The Internet's impact on the American political system. New York: Oxford University Press.

Drinkard, J. (1999, August 31). Internet transforming US politics. USA Today. Downloaded August 31, 1999.

FitzGerald, E. \& McNutt, J.G. (1999). Electronic advocacy in policy practice: A framework for teaching technologically based practice. Journal of social work education. 35 (3), 331-341.

Haynes, K.S. \& Mickelson, J.S. (2000). Affecting change. [Fourth Edition] New York: Longmans.

Haywood, T. (1995). Info rich/info poor : access and exchange in the global information society. London ; New Jersey: Bowker-Saur.

Hoefer-R.A; Hoefer-R; Tobias-R.A (1994). Geographic information systems and human services. Journal of Community-Practice.1(3): 113-28, 1994.

Krause, A., Stein, M. \& Clark, J. (1998). The Virtual activist: A Training course. Netaction. On-Line at http://www.netaction.org/training/

Lang, J., \& St. John's University (New York, N. Y.) (1988). Unequal access to information resources: problems and needs of the world's information poor : proceedings of the Congress for Librarians, February 17, 1986, including related invited papers and a classified bibliography. Ann Arbor, Mich.: Pierian Press.

Lemmon, P. \& Carter, M. (1998). Speaking up in the Internet age. Washington, DC: OMBWatch.

McConnaughey, J. Everette, D.W. Reynolds, T. \& Lader, W. (1999). Falling through the net: defining the digital divide. Washington, DC: National Telecommunications and Information Administration, U.S. Department of Commerce.

McNutt, J.G. \& Penkauskas, K. (2000, April). Electronic advocacy. Presentation at Getting Wired: Advocacy in Cyberspace. The First Boston College Conference on Electronic Advocacy in Social Work Practice, Chestnut Hill, MA, April 14, 2000. 
McNutt, J.G (2000). Coming Perspectives in the Development of Electronic Advocacy for Social Policy Practice. Critical Social Work, 1 (1).

McNutt, J.G. \& Boland, K.M. (1999). Electronic Advocacy by Non-Profit Organizations in Social Welfare Policy. Non-profit and Voluntary Sector Quarterly. 28 (4), 432-451.

McNutt, J.G, Bartron, J. \& Boland, K.M. (1999, November). An Empirical Study of Electronic Fundraising Activity in a Group of Non-profits. Paper read at the 28th Annual meeting of the Association of Voluntary Action Scholars, Arlington, VA

McNutt, J.G., Lima, J., Penkaukaus, K \& Rusoff, M. (1999, November). A Study of the Impact of Internet Based Technologies on the Legislative Process at the State Level. Paper read at the $28^{\text {th }}$ Annual meeting of the Association for Research on Nonprofit Organizations and Voluntary Action, Arlington, VA.

McNutt, J.G. (1998). Ensuring social justice for the new underclass: Community interventions to meet the needs of the new poor. In Ebo, B.(ed.) (1998). The Cyberghetto or Cybertopia: Race, Class, Gender \& Marginalization in Cyberspace. New York: Praeger, pp. 33-47.

Rees, S. (1999). Strategic choices for non-profit advocates. Nonprofit and Voluntary Sector Quarterly. 28 (1), 65-73.

Rheingold, H. (1993). The Virtual Community: Homesteading on the Electronic Frontier. Boston: Addison-Wesley Publishing Company.

Rogers, E.M. (1995). The Diffusion of innovation. [Fourth Edition]. New York: Free Press.

Schwartz, E. (1996). NetActivism: How Citizens use the Internet. Sebastopol: O'Reilly.

Schlossberg, M. (1998). Asset Mapping and community development planning with GIS: A look at the heart of West Michigan United Way's Innovative Approach . Paper presented at the 27th Annual Meeting of the Association for Research on Nonprofit Organizations and Voluntary Action, Seattle, WA.

Schuler, D. (1996). New Community networks: Wired for change. Reading, MA: Addison-Wesley.

Smucker, R. (1999). The nonprofit lobbying guide . [Second Edition] Washington:, DC: Independent Sector.

Tropman, J.E., J.L. Erlich \& J. Rothman (Eds.) Tactics and techniques of community intervention (3rd ed). Itasca IL: Peacock, 1995, 103-113.

Turner, R. (1998). Democracy at work: Non-profit use of Internet technology for public policy purposes. Washington, DC: OMB Watch. 
Wresch, W. (1996). Haves and Havenots in the Information Age. New Brunswick: Rutgers University Press.

Wresch, W. C. (1995). Disconnected: Haves and Have-Nots in the Information Age. New Brunswick NJ: Rutgers University Press.

Roger A. Lohmann is the founder and operator of both the ARNOVA-L (1990) and ACOSA-L (1992) discussion lists. John McNutt is the founder and chair of the Information Technology Symposium for the CSWE Annual Program Meeting and created the original ACOSA website. 